\title{
Esophageal cancer in Aleppo, Syria 2010-2020: a rare cancer in a war zone
}

\author{
Samer Alhames ${ }^{1}$, Andrew Hsu ${ }^{2}$, Fadi Rustam ${ }^{3}$, Rami Kassar ${ }^{4}$, Mohamad bisher Shihade ${ }^{4}$, \\ Khaldoun Almhanna ${ }^{2}$
}

${ }^{1}$ Department of Thoracic Surgery, St Louis Hospital, Aleppo, Syria; ${ }^{2}$ Division of Hematology/Oncology, The Warren Alpert Medical School of Brown University, Lifespan Cancer Institute, Rhode Island Hospital, Providence, RI, USA; ${ }^{3}$ Department of Oncology, ${ }^{4}$ Department of Surgery, St Louis Hospital, Aleppo, Syria

Contributions: (I) Conception and design: S Alhames, A Hsu, K Almhanna; (II) Administrative support: None; (III) Provision of study materials or patients: None; (IV) Collection and assembly of data: None; (V) Data analysis and interpretation: None; (VI) Manuscript writing: All authors; (VII) Final approval of manuscript: All authors.

Correspondence to: Khaldoun Almhanna, MD. Division of Hematology/Oncology, The Warren Alpert Medical School of Brown University, Lifespan Cancer Institute, Rhode Island Hospital, 593 Eddy St, George 353, Providence, RI 02903, USA. Email: Kalmhanna@lifespan.org.

\begin{abstract}
The management of diseases such as cancer in developing countries are often suboptimal given a lack of resources and access to specialists and therapeutics. In March 2020, Syria descended into its ninth year of the war with a rising death toll and millions of Syrian refugees. Aside from the inherent dangers of war, cancer care during war is especially difficult with partially or non-functional infrastructure due to destruction, inconsistent electrical power, inaccessibility, or the inherent dangers of living in a war zone. Furthermore, limitations to therapeutics are exacerbated when supply chains responsible for bringing in essential medications such as chemotherapeutics are disrupted by international economic sanctions. Aleppo, Syria is the site of some of the fiercest fighting which ended in December 2016. Since then, Aleppo has made a slow recovery to rebuild its infrastructure while the war continues elsewhere in the country. In this article, we aim to highlight the challenges in the management of cancer, particularly esophageal cancer, during a time of war in Aleppo, Syria. We aim to discuss current challenges and limitations to care in a war zone. We will also touch upon areas of need for continued improvement in the care of cancer patient's in Aleppo, Syria.
\end{abstract}

Keywords: Esophageal cancer; cancer; Aleppo; Syria; global oncology

Submitted Jun 04, 2020. Accepted for publication Jul 10, 2020.

doi: $10.21037 /$ atm-20-4474

View this article at: http://dx.doi.org/10.21037/atm-20-4474

\section{Introduction}

In developing countries, patients with cancer receive suboptimal care for a number of reasons including no availability of modern imaging, subspecialty oncology services, or interventional specialties; and the lack of access to newer chemotherapeutics, multidisciplinary teams, clinical trials, and health insurance coverage. In March 2020, Syria descended into its ninth year of a war that has claimed the lives of thousands of civilians and displaced many more citizens seeking refuge from the ongoing fighting.
Cancer management has been particularly difficult during this period with much of the healthcare infrastructure destroyed or inaccessible. In Aleppo, the second most populated city in Syria along with other metropolises in Syria, cancer treatment services were traditionally provided free of charge in public health facilities. Private practices were also available and treated patients based upon a fee-per-service model. As a direct result of the crisis, many treatment plans of cancers patients have been compromised by the destruction of some of these facilities compounded with shortages of specialized staff, equipment, and medications. On the other hand, access to cancer care 
in certain areas of the country is hazardous and leads to infrequent follow-ups that are required to provide optimal care. The path to receive cancer care for Syrians during war time is dangerous. Although published by the World Health Organization (WHO), the exact number of deaths from non-communicable diseases such as cancer due to a lack of access to medical care and treatment is unclear (1).

The aim of this review article is to highlight the challenges in management of cancer, particularly esophageal cancer, during a time of war by focusing on cancer care in Aleppo, Syria. A general overview of the standard of care management of esophageal cancer will be first provided, then cancer care in Aleppo, Syria during the war will be discussed and with a specific focus on esophageal cancer, its challenges, and limitations in the care of this malignancy in a war zone.

We present the following article in accordance with the Narrative Review reporting checklist (available at http:// dx.doi.org/10.21037/atm-20-4474).

\section{Esophageal cancer}

Esophageal cancer is the seventh most common malignancy worldwide with an incidence of 572,034 new cases in 2018, representing $3.2 \%$ of all new cancer cases. Furthermore, esophageal cancer is the sixth most common cause of cancer-related deaths accounting for $5.8 \%$ or 508,585 cancer-related deaths in 2018 (2). In Syria, esophageal cancer is the twenty-sixth most common malignancy with an estimated incidence of 104 new cases in 2018, representing $0.45 \%$ of all new cancers. In 2018 , esophageal cancer accounted for 99 deaths or $0.66 \%$ of all cancerrelated deaths, ranking twenty-second in Syria. In both Syria and worldwide, men outnumber women at a 3:1 ratio in incidence and in cancer-related deaths $(2,3)$.

There are two major histological subtypes of esophageal cancer: adenocarcinoma (EAC) and squamous cell carcinoma (ESCC). In Western countries over the past half century, EAC has become the most common subtype and this shift has been attributed to lifestyle changes including decreased rates of tobacco and alcohol use coupled with an increased rate of obesity and its associated comorbidities such as gastroesophageal reflux disease (GERD) or Barrett's esophagus $(4,5)$. Worldwide and in Syria, squamous cell carcinoma remains the predominant subtype. In Western countries, $90 \%$ of ESCC can be associated with smoking and alcohol consumption; however, in higher prevalence areas such as the "Asian esophageal cancer belt" which consists of countries which extend along the ancient Silk Road trading route, alcohol use is not as prevalent and other predisposing risk factors have been identified-low fruit and vegetable intake, drinking hot tea, use of opium and tobacco products, Helicobacter pylori infections, inhalation of polycyclic aromatic hydrocarbons through burning of wood or road traffic, poor oral hygiene, consumption of funguscontaminated food, and low socioeconomic status (6-8).

Patients with early stage esophageal cancer are typically asymptomatic though can have symptoms of progressive dysphagia, odynophagia, and/or weight loss depending on the location of the tumor. Given its indolent nature, nearly half of all patients remain asymptomatic and are found to have unresectable or metastatic disease at time of diagnosis. As a result, the five-year survival rate for esophageal cancer can range from $4 \%$ to $40 \%$ depending on the stage at diagnosis, with an overall 5 -year survival rate of $18 \%$ (9). For early stage disease, multimodality treatment is preferred, which consists of a combination of surgery and chemotherapy with or without radiation. Multiple strategies exist on whether to administer neoadjuvant and/ or adjuvant chemotherapy and is often dependent upon the region of the world in which a patient is being treated (10). Regardless of the strategy, surgery with an esophagectomy with reconstructive surgery is considered to play a pivotal role in achieving locoregional control and offering the best chance for cure in early stage disease (11). There are three common techniques used for esophagectomies: transthoracic esophagectomy (TTE) with an abdominal and right thoracic incision (Ivor Lewis); TTE with a neck and right thoracic incision (McKeown); and a transhiatal esophagectomy (THE). Of note, randomized trials and meta-analyses comparing TTE $v s$. THE have shown no significant differences in outcomes between the different approaches $(12,13)$. The extent of lymph node dissection varies between histological subtypes and regional differences in management (14). Unfortunately, since nearly half of patients are found to have unresectable or metastatic disease at time of diagnosis, the opportunity for cure through surgical resection is often lost.

In the setting of unresectable or metastatic disease, the prognosis remains poor and traditional systemic treatments have led to modest improvements in overall survival when compared to best supportive care alone. In the frontline setting, systemic treatments consist of a combination of a fluoropyrimidine (5-fluorouracil, capecitabine, S-1) and a platinum agent (cisplatin, oxaliplatin) with the addition of docetaxel if a patient has a good performance 
Table 1 Available resources in Syria

\begin{tabular}{lll}
\hline Resources & Damascus & Aleppo \\
\hline Blood transfusions & Available & Available \\
Granulocyte colony-stimulating factors & Available & Available \\
Chemotherapy & Available & Available \\
Targeted agents & Limited & Limited \\
Onsite blood tests & Available & Available \\
Radiation therapy & Available & Not Available \\
Surgical oncologist & Limited & Limited \\
Oncology clinical trials & Not Available & Not Available \\
Endoscopic ultrasound/endobronchial US & Available & Not Available \\
Interventional radiology & Limited & Not Available \\
Esophageal stent & Available & Not Available \\
Pet scan & Available & Not Available \\
Screening & Limited & Limited \\
\hline
\end{tabular}

status and good organ function (15-17). In countries where trastuzumab is readily available, this is added to a fluoropyrimidine and platinum doublet for human epidermal growth factor receptor-2 (HER2)-positive disease (18). In the second-line setting, traditional cytotoxic chemotherapy is administered through varying strategies; however, in resource-rich countries, ramucirumab, an antivascular endothelial growth factor (VEGF) monoclonal antibody, is added to paclitaxel (19). Furthermore, tumors which express programmed death protein-1 (PD-1) are eligible for immunotherapy in countries fortunate enough to have access (20).

\section{Cancer care in Aleppo, Syria between 2010 to 2020}

In general, cancer treatment is challenging and especially the case in developing countries. Little information is available about cancer treatment in Syria before the war. In 2008, there were an estimated 9,468 new cases of cancer in Syria; however, the incidence of new cancer diagnoses since then is unknown as the national cancer registry was deactivated in 2009 resulting in no further statistics or reports (21). A lack of a national cancer registry makes it difficult to compare outcomes with other countries as well as within the different facilities in Syria. Furthermore, the exact incidence of new cancer cases can be challenging with such limited information. As a result, current estimates and statistics are based upon independent third parties such as the Global Cancer Observatory (GLBOCAN) whose data is based upon statistical modeling when local registry data is unavailable (22). During a time of war, those who remain in Syria are left with limited medical and cancer care given a lack of infrastructure and resources because of western sanctions.

Since December 2016, the infrastructure in Aleppo has slowly recovered-for outpatient health centers, 21 are fully functional, 44 are partially functional, and 162 are nonfunctional due to safety reasons, damage to infrastructure, or disruptions in electricity. As for hospitals, 7 are fully functional, 4 are partially functional, and 4 are nonfunctional $(23,24)$. While the infrastructure is slowly being rebuilt, the availability of specialists continues to be sparse with the continued war in Syria.

Prior to the start of the war, there was an estimated 33,000 physicians and 120 hematologist/oncologist in Syria; however, since the start of the war, more than $50 \%$ of physicians have fled, leading to a shortage of hematologist/ oncologist throughout Syria (25). In addition to the limitations in infrastructure and specialist care, diagnostic and supportive care can also be limited depending upon the region while certain therapies are unavailable throughout Syria (Table 1). While chemotherapeutic agents from the expanded WHO List of Essential Medicines are available in 
Table 2 WHO Model List of Essential Medications 2010 versus 2019 (26)

\begin{tabular}{|c|c|}
\hline $\begin{array}{l}\text { WHO Essential Medicines List } \\
(\text { EML) in } 2010 \text { (Pre-War) }\end{array}$ & $\begin{array}{l}\text { Cancer Medicines added on } \\
\text { the WHO EML } 2019\end{array}$ \\
\hline Asparaginase & Arsenic trioxide \\
\hline Azathioprine & Adalimumab \\
\hline Bleomycin & Bendamustine \\
\hline Calcium folinate & Capecitabine \\
\hline Carboplatin & Cisplatin \\
\hline Chlorambucil & Docetaxel \\
\hline Cyclophosphamide & Fludarabine \\
\hline Cyclosporine & Gemcitabine \\
\hline Cytarabine & Irinotecan \\
\hline Dacarbazine & Melphalan \\
\hline Dactinomycin & Oxaliplatin \\
\hline Daunorubicin & Paclitaxel \\
\hline Doxorubicin & Peg-asparaginase \\
\hline Etoposide & Vinorelbine \\
\hline Fluorouracil & All-trans retinoid acid (ATRA) \\
\hline Hydroxycarbamide & Bortezomib \\
\hline Ifosfamide & Dasatinib \\
\hline Mercaptopurine & Erlotinib \\
\hline Mesna & Imatinib \\
\hline Methotrexate & Nilotinib \\
\hline Procarbazine & Rituximab \\
\hline Vinblastine & Trastuzumab \\
\hline Vincristine & Filgrastim \\
\hline Allopurinol & Lenalidomide \\
\hline Dexamethasone & Nivolumab \\
\hline Hydrocortisone & Thalidomide \\
\hline Prednisolone & Abiraterone \\
\hline \multirow[t]{5}{*}{ Tamoxifen } & Anastrozole \\
\hline & Bicalutamide \\
\hline & Leuprorelin \\
\hline & Methylprednisolone \\
\hline & Zoledronic Acid \\
\hline
\end{tabular}

major cities through Syria, newer chemotherapeutics such as immunotherapies or targeted therapies, which are critical in improving outcomes in the management of cancers in developed nations, remain limited given availability and expense (Table 2) (26). Furthermore, despite medications being designated as "essential" by the WHO, Syrian hospitals have reported an inconsistent supply of "essential" cytotoxic chemotherapeutics leading to delays in treatment, sometimes on the order of months. Unavailability of these essential medications can be attributed to unreliable supply chains secondary to international economic sanctions and patients being unable to afford these medications with deflation-it is estimated that $15 \%$ of cancer care and $17 \%$ of chemotherapy costs are paid for out-ofpocket while $3 \%$ of cancer care and $8 \%$ of chemotherapy costs are paid for through insurance, and less than $10 \%$ of costs are supplemented by private donations and/or non-governmental organizations (NGOs). Meanwhile, government facilities continue to be the main provider of cancer care, free of charge, across Syria (23).

\section{Management of esophageal cancer in Aleppo, Syria}

Data on the treatment of early stage esophageal cancer is non-existent as screening is not well established and patients mostly present at an advanced stage. In our experience, ESCC is the most common pathology seen in Aleppo and smoking remains the major risk factor as heavy alcohol consumption is rare. During the initial work-up for esophageal cancer at our institution, onsite blood testing along with more advanced diagnostic tools such as barium swallow studies, upper endoscopy, imaging [i.e., computed tomography (CT), magnetic resonance imaging (MRI)], echocardiogram bronchoscopy, and chest/abdominal laparoscopy are available to assist in obtaining a diagnosis. Positron emission tomography (PET) imaging, endoscopic ultrasound (EUS) with paraesophageal ganglion biopsies, and endobronchial ultrasound (EBUS) with transbronchial biopsies are not available and patients often are required to travel to Damascus, Syria. Given the expense of traveling, these additional diagnostic tests are often not performed, and the extent of disease is frequently underestimated. Similar to the trend in many other cancers in the area, the majority of those diagnosed often have advanced stage 
disease which can be attributed to the inherent and insidious nature of esophageal cancer in addition to delays in seeking out medical attention and minimization of symptoms in the setting of ongoing war (23).

Once a tissue diagnosis is made, the patient is often first referred to a surgical oncologist. During that initial encounter, there is an extensive discussion about the use of adjuvant or neoadjuvant chemotherapy or radiation therapy. Of note, radiation oncology is only available in certain major cities throughout Syria (Table 1). Due to cultural beliefs the patients often present with a preconceived notion that surgical resection is curable regardless of stage and is distrustful and skeptical about the role of other modalities. Given this fact, pre-operative chemoradiation is rarely accepted by patients who believe in surgery as a radical treatment for their cancer. Furthermore, this preconceived notion can be problematic and can be detrimental to patients who present with metastatic disease and demand surgery to palliate symptoms as complimentary techniques such as stent placement or laser ablation are unavailable in Aleppo, but available in Damascus. It is important to note that while radiation oncologists are available in other centers in Syria, they are not available in Aleppo due to damaged infrastructure during the war. As a result, definitive chemoradiation is rarely performed.

In Aleppo, laparoscopic esophagectomies have not been implemented due to a lack of specialized centers along with the higher costs associated with laparoscopy. Therefore, esophagectomies are still dependent upon laparotomy. Patients are usually admitted to the hospital a day or two prior to surgery to maximize their lung function. Selective intubation technique is used during anesthesia when an open-chest surgery is performed. Central lines and arterial catheters are rarely needed. The most common techniques used are Ivor Lewis TTE or THE for high-risk patients or ESCC. Furthermore, a gastric conduit is used as a replacement after esophagectomy and the esophagogastric anastomosis is traditionally done by hand due to the higher cost of using a stapler; however, more recently the LigaSure ${ }^{\circledR}$ Vessel Sealing System has been used for releasing the stomach (27). A pyloroplasty is routinely done to avoid post-surgical gastroduodenal emptying problems due to the lack of endoscopic pyloric dilation when needed. Celiac lymph node dissection is done routinely, and mediastinal lymph node dissections are performed if thoracotomy is done. Surgical closing is done with one thoracic drain or negative pressure drains in the cervical area. The estimated surgical duration is 180 minutes. Patients rarely require blood transfusion and the average estimated blood loss is between 500-700 milliliters. The patient is then extubated and transferred to the intensive care unit. Furthermore, a jejunostomy is usually done for post-operative nutrition until the patient is able to tolerate oral nutrition. Parenteral nutrition, when available, is very costly. On post-operative day 5 , the anastomosis is evaluated using methylene blueif the drains are clear of methylene blue, the drains are removed and the patient is started on a liquid diet. Patients are typically discharged after a week-long hospitalization and placed on a liquid diet for an additional week with instructions to slowly advance to a regular diet as tolerated. Intraoperative bleeding is the most common surgical complication. Other commonly seen early complications include respiratory failure, atrial fibrillation and wound infection. Post-surgically, the most common complication seen is an esophagogastric anastomotic stenosis which requires a referral to Damascus where stenting is available. Our surgical mortality rate between 2010-2020 has been approximately 5-6\% largely due to anastomotic leak. Once the histopathologic results of the resected specimen and lymph nodes have resulted, a referral to medical oncology is made.

Cytotoxic chemotherapy is available in the palliative setting for unresectable or metastatic disease and is also available post-operatively for fit patients without comorbidities. Similar to developed countries, systemic therapies consist of a combination of a fluoropyrimidine and platinum agent with the addition of docetaxel in fit patients with minimal co-morbidities. While the WHO list of essential medications has expanded over the past decade, the availability of therapeutics outside of cytotoxic chemotherapy is limited. Trastuzumab is available and has been used for the treatment of HER2-positive breast cancer in highly selected populations. Data on its use in metastatic HER2-positive gastric and esophageal cancer in Syria is unknown. Ultimately, HER2-positive is inconsequential in this setting given the lack of access to HER2-directed therapies. Lastly, ramucirumab is not on the WHO list of essential medications and unavailable for use (26).

Follow-up with both the surgical oncologist for surveillance exams and medical oncologist is variable and can be poor given financial constraints, logistics of travel, patient safety, and caring for oneself in a war zone after receiving chemotherapy, disruption of health services and infrastructure, or cultural beliefs regarding the efficacy of chemotherapy. As a result, around $81 \%$ of cancer patients in Syria complete systemic treatment with only $55 \%$ of 
patients being able to complete systemic treatment without any interruptions (24). The specific data on esophageal cancer is not available.

\section{Conclusions and future direction}

Cancer care during a time of war presents its own unique set of problems. In Aleppo, which was the site of one of the fiercest and most destructive battles in the entire war, its infrastructure was severely damaged and it has been left with only a handful of oncologist to provide cancer care to a large population. Despite these setbacks and limitations, surgeons and oncologists have continued to provide care to patients as their city infrastructure slowly rebuilds. Moving forward, in regard to esophageal cancer management in Aleppo: first, patient education on the role of neoadjuvant/ adjuvant therapy need to be emphasized; second, several modalities are needed to established the exact stage of the disease including EUS, PET scans, and in some cases EBUS; third, palliative treatment and endoscopic lumen restoration are lacking at this time; and last but most importantly, a radiation therapy center within the city is desperately needed to deliver neoadjuvant/adjuvant or even palliative treatment. As the city moving toward recovery, a specialized surgical center for esophageal cancer with endoscopic and video assisted surgery will be optimal.

\section{Acknowledgments}

Funding: None.

\section{Footnote}

Provenance and Peer Review: This article was commissioned by the Guest Editor (Dr. Khaldoun Almhanna) for the series "Gastroesophageal Cancer 2020" published in Annals of Translational Medicine. The article was sent for external peer review organized by the Guest Editor and the editorial office.

Reporting Checklist: The authors have completed the Narrative Review reporting checklist. Available at http:// dx.doi.org/10.21037/atm-20-4474

Conflicts of Interest: All authors have completed the ICMJE uniform disclosure form (available at http://dx.doi. org/10.21037/atm-20-4474). The series "Gastroesophageal Cancer 2020" was commissioned by the editorial office without any funding or sponsorship. KA served as the unpaid Guest Editor of the series and serves as an unpaid editorial board member of Annals of Translational Medicine from Nov 2019 to Oct 2021. KA reports personal fees from Merck, outside the submitted work. The other authors have no other conflicts of interest to declare.

Ethical Statement: The authors are accountable for all aspects of the work in ensuring that questions related to the accuracy or integrity of any part of the work are appropriately investigated and resolved.

Open Access Statement: This is an Open Access article distributed in accordance with the Creative Commons Attribution-NonCommercial-NoDerivs 4.0 International License (CC BY-NC-ND 4.0), which permits the noncommercial replication and distribution of the article with the strict proviso that no changes or edits are made and the original work is properly cited (including links to both the formal publication through the relevant DOI and the license). See: https://creativecommons.org/licenses/by-nc-nd/4.0/.

\section{References}

1. World Health Organization. Non-communicable diseases country profiler 2018: Syrian Arab Republic. Available online: https://www.who.int/nmh/countries/2018/syr_ en.pdf?ua $=1$

2. World Health Organization International Agency for Research on Cancer (IARC). GLOBOCAN 2018: Oesophagus Fact Sheet. Available online: https://gco. iarc.fr/today/data/factsheets/cancers/6-Oesophagus-factsheet.pdf

3. World Health Organization International Agency for Research on Cancer (IARC). GLOBOCAN 2018: Syrian Arab Republic Fact Sheet. Available online: https://gco. iarc.fr/today/data/factsheets/populations/760-syrian-arabrepublic-fact-sheets.pdf

4. Islami F, Fedirko V, Tramacere I, et al. Alcohol drinking and esophageal squamous cell carcinoma with focus on lightdrinkers and never-smokers: a systematic review and metaanalysis. Int J Cancer 2011;129:2473-84.

5. Engel LS, Chow WH, Vaughan TL, et al. Population attributable risks of esophageal and gastric cancers. J Natl Cancer Inst 2003;95:1404-13.

6. Zhang HZ, Jin GF, Shen HB. Epidemiologic differences in esophageal cancer between Asian and Western populations. Chin J Cancer 2012;31: 281-86. 
7. Sadjadi A, Marjani H, Semnani S, et al. Esophageal Cancer in Iran: A Review. Middle East J Cancer 2010;1:5-14.

8. Gholipour M, Islami F, Roshandel G, et al. Esophageal Cancer in Golestan Province, Iran: A Review of Genetic Susceptibility and Environmental Risk Factors. Middle East J Dig Dis 2016;8:249-66.

9. Fitzmaurice C, Allen C, Barber RM, et al. Global, Regional, and National Cancer Incidence, Mortality, Years of Life Lost, Years Lived With Disability, and DisabilityAdjusted Life-years for 32 Cancer Groups, 1990 to 2015: A Systematic Analysis for the Global Burden of Disease Study. JAMA Oncol 2017;3:524-48.

10. Lutz MP, Zalcberg J, Ducreux M, et al. Highlights of the EORTC St. Gallen international expert consensus on the primary therapy of gastric, gastroesophageal and oesophageal cancer-differential treatment strategies for subtypes of early gastroesophageal cancer. Eur J Cancer 2012;48:2941-53.

11. Sohda M, Kuwano H. Current Status and Future Prospects for Esophageal Cancer Treatment. Ann Thorac Cardiovasc Surg 2017;23:1 11.

12. Barreto JC, Posner MC. Transhiatal versus transthoracic esophagectomy for esophageal cancer. World J Gastroenterol 2010;16:3804-10.

13. Rentz J, Bull D, Harpole D, et al. Transthoracic versus transhiatal esophagectomy: a prospective study of 945 patients. J Thorac Cardiovasc Surg 2003;125:1114-20.

14. Hagens ERC, van Gerg Henegouwen MI, Cuesta MA, et al. The extent of lymphadenectomy in esophageal resection for cancer should be standardized. J Thorac Dis 2017;9:S713-23.

15. Van Cutsem E, Moiseyenko V, Tjulandin S, et al. Phase III study of docetaxel and cisplatin plus fluorouracil compared with cisplatin and fluorouracil as first-line therapy for advanced gastric cancer: a report of the V325 Study Group. J Clin Oncol 2006;24:4991-97.

16. Shah MA, Janjigian YY, Stoller R, et al. Randomized Multicenter Phase II Study of Modified Docetaxel, Cisplatin, and Fluorouracil (DCF) Versus DCF Plus Growth Factor Support in Patients with Metastatic Gastric Adenocarcinoma: A Study of the US Gastric Cancer Consortium. J Clin Oncol 2015;33:3874-79.

17. Cunningham D, Starling N, Rao S, et al. Capecitabine and oxaliplatin for advanced esophagogastric cancer. N Engl J Med 2008;358:36-46.

18. Bang YJ, Van Cutsem E, Feyereislova A, et al. Trastuzumab in combination with chemotherapy versus chemotherapy alone for treatment of HER2-positive advanced gastric or gastro-oesophageal junction cancer (ToGA): a phase 3, open-label, randomised controlled trial. Lancet 2010;376:687-97.

19. Wilke H, Muro K, Van Cutsem E, et al. Ramucirumab plus paclitaxel versus placebo plus paclitaxel in patients with previously treated advanced gastric or gastro-oesophageal junction adenocarcinoma (RAINBOW): a double-blind, randomised phase 3 trial. Lancet Oncol 2014;15:1224-35.

20. Fuchs CS, Doi T, Jang RW, et al. Safety and Efficacy of Pembrolizumab Monotherapy in Patients With Previously Treated Advanced Gastric and Gastroesophageal Junction Cancer: Phase 2 Clinical KEYNOTE-059 Trial. JAMA Oncol 2018;4:e180013.

21. National Cancer Institute Radiation Research Program: Human Resources for Treating New Cancer Cases in Syria. Available online: http://rrp.cancer.gov/ programsResources/lowIncome/syria.pdf

22. Global Cancer Observatory (GLOBOCAN). New Global Cancer Data: GLOBOCAN 2018. Available online: https://www.uicc.org/news/new-global-cancer-dataglobocan-2018

23. World Health Organization Health Resources Availability Monitoring System (HeRAMS). Syrian Arab Republic annual report 2018: public health centers. Available online: https://applications.emro.who.int/docs/syr/CoPub_ HeRAMS_annual_rep_public_health_2019_en.pdf?ua=1

24. World Health Organization Health Resources Availability Monitoring System (HeRAMS). Syrian Arab Republic annual report 2018: public hospitals. Available online: https://applications.emro.who.int/docs/syr/CoPub_ HeRAMS_annual_rep_public_Hospitals_2019_ EN.pdf?ua=1

25. World Health Organization: Global Health Observatory (GLOBOCAN) data repository. Available online: http:// apps.who.int/gho/data/? theme=home\&vid=19200andthem $\mathrm{e}=$ country

26. World Health Organization (WHO): Model List of Essential Medications. Available online: https://www.who. int/medicines/publications/essentialmedicines/en/

27. Eroglu A, Turkyilmaz A, Aydin Y, et al. The Use of the LigaSure Vessel Sealing System in Esophageal Cancer Surgery. Ann Thorac Surg 2007;84:2076-9.

Cite this article as: Alhames S, Hsu A, Rustam F, Kassar R, Shihade MB, Almhanna K. Esophageal cancer in Aleppo, Syria 2010-2020: a rare cancer in a war zone. Ann Transl Med 2020;8(17):1105. doi: 10.21037/atm-20-4474 